A N N A L E S

UNIVERSITATIS M A R I A E C URIE-SKŁODOW S K A

LUBLIN - POLONIA

VOL. LXXII

SECTIO F

2017

Universität Paderborn

HERMANN KAMP

Hermann.Kamp@uni-paderborn.de

\title{
Friedensstiftung und Autonomiebestrebungen in den Städten des hohen Mittelalters. Zur Bedeutung ritueller Unterwerfungen vor dem bischöflichen Stadtherrn
}

Utrzymywanie pokoju a autonomia miejska w miastach średniowiecznych.

$\mathrm{O}$ znaczeniu rytualnego ukorzenia się przed biskupimi panami miasta

\section{ZUSAMMENFASSUNG}

Der vorliegende Aufsatz geht der Frage nach, welche Funktion und welchen Stellenwert rituelle Unterwerfungen bei der Beilegung von Konflikten zwischen Stadtbürgern und ihren bischöflichen Stadtherrn im römisch-deutschen Reich vor 1300 besaßen. Anhand der Kölner Unterwerfungen von 1074 und 1258 sowie der rituellen Selbstdemütigung der Paderborner Bürger im Jahr 1222 wird exemplarisch aufgezeigt, dass sich selbst in den Unterwerfungen, die die Unterordnung der Stadtgemeinschaft symbolisch festhalten, der Aufstieg und die wachsende Autonomie der Städte widerspiegeln. Dabei steht die frühe an den Formen der Kirchenbuße ausgerichtete Kölner Unterwerfung für die Behauptung eines ungeminderten Strafanspruchs des Stadtherrn, dem nur geringe Grenzen gesetzt waren, weil es keine Vermittler gab, die ihn auf ein bestimmtes Verhalten hätten verpflichten können. Insofern offenbart das Engagement von Vermittlern in den beiden anderen Konflikten das gewachsene Prestige der städtischen Oberschichten, die nun als Verhandlungspartner anerkannt wurden, denen gegenüber man sich auch verpflichtete. Während es in Paderborn 1222 noch allein die Forderungen des Bischofs waren, die in der Sühneurkunde Aufnahme fanden, wurden bei der Beendigung der Kölner Konflikts von 1258 zwei mehr oder minder paritätisch aufgebaute Urkunden auf- und ein Schiedsgericht eingesetzt, das über die Klagen beider Seiten befinden und einen Ausgleich schaffen sollte. Damit war die Stadt dem Bischof als Konfliktgegner gleichgestellt. Gerade das letzte Beispiel führt deutlich vor Augen, wie der Stellenwert der rituellen Unterwerfung im Rahmen der Konfliktbeilegung abnahm, weil die Abgrenzung der Rechtsansprüche zwischen Stadtherr und Stadt gegenüber der Bestrafung des Ungehorsams in den Vordergrund trat. Infolgedessen rückte auch das Schiedsurteil ins Zentrum der Konfliktbeilegung. Dennoch konnte die rituelle Unterwerfung mit der wachsenden Autonomie der Städte nicht ganz verdrängt werden. Sie blieb ein sinnvolles Instrument, um Vergehen zu 
benennen und zu vergeben, um exkommunizierten Sündern die Wiederaufnahme in die Kirche zu bahnen, um die Ehre des Stadtherrn wiederherzustellen und um Herrschaftsverhältnisse sichtbar neu zu begründen.

Schlüsselwörte: Unterwerfung; Köln 1074; Lampert von Hersfeld; Kirchenbuße; Vermittlung; Paderborner Sühne von 1222; städtische Autonomie; Schiedsverfahren

Seit dem 10. Jahrhundert lösten die Könige und die Großen im römisch-deutschen Reich zusehends ihre bewaffneten Konflikte auf dem Weg einer rituellen Unterwerfung, einer deditio, wie die Zeitgenossen sagten. Dabei traten die hochrangigen Herren, die sich zur Unterwerfung bereitfanden, in demütigem Aufzug vor den König, bekräftigten ihre Reue und übergaben sich in dessen Gewalt. Im Gegenzug verzichtete der Herrscher darauf, sie mit dem Tod zu bestrafen, und versprach Milde walten zu lassen, wenn er sie zur Verantwortung ziehen wollte ${ }^{1}$. Im Zuge dieser vom kirchlichen Bußritual inspirierten Form der Konfliktbeilegung gewann auch die Vermittlung als Verfahren der Friedensstiftung festere Konturen. Ausgehandelt wurden diese Unterwerfungen nämlich nicht selten von Personen, die enge Beziehungen zu beiden Konfliktparteien besaßen ${ }^{2}$. Obschon solche Friedensvermittler zumeist im Lager des Königs standen, erlangten sie im Zuge der Verhandlungen mit der gegnerischen Partei eine eigenständige Position, aus der heraus sie die Streitgegner zu einer einvernehmlichen Lösung zu bewegen suchten ${ }^{3}$. Sichtbar wurde ihre eigenständige Rolle in dem Moment, in dem sie den Herrscher zu einer gnädigen Behandlung seiner Gegner verpflichten konnten und dafür ihr Wort bei denjenigen einlegten, die sich unterwerfen wollten. Ein solches Handeln setzte bereits ein gewachsenes Selbstbewusstsein der Großen gegenüber dem König voraus ${ }^{4}$. Nicht weniger offenbart der an die Unterwerfung anschließende Gnadenakt die Rücksichten, die ein König gegenüber aufständischen Großen nehmen musste. So breitete sich denn auch diese Art der Konfliktbeilegung in dem Zeitraum aus, in dem die Fürsten gegenüber dem Königtum an

1 Vgl. grundlegend zur rituellen Unterwerfung G. Althoff, Das Privileg der deditio. Formen gütlicher Konfliktbeendigung in der mittelalterlichen Adelsgesellschaft, [in:] Spielregeln der Politik im Mittelalter. Kommunikation in Frieden und Fehde, Darmstadt 1997, S. 99-125; idem, Die Macht der Rituale. Symbolik und Herrschaft im Mittelalter, Darmstadt 2007, S. 67-84, sowie die grundlegenden Überlegungen von J.-M. Moeglin, Pénitence publique et amende honorable au Moyen Age, „Revue Historique“ 1997, Vol. 298, S. 225-269, bes. 226-227 u. 231ff., der das Verhältnis von kirchlicher Buße, politischem Versöhnungsgestus und der Harmschar analysiert.

2 Vgl. hierzu und zum Folgenden H. Kamp, Friedensstifter und Vermittler im Mittelalter, Darmstadt 2001, S. 162ff.

3 Bezeichnenderweise nannte man sie mediatores pacis, was nicht auf ihre Stellung zwischen den Konfliktparteien, sondern auf ihre Tätigkeit als Friedensstifter abhob. Vgl. ibidem, S. 18-20 u. 128.

4 Vgl. ibidem, S. 177. 
Handlungsspielraum gewannen und zusehends Verantwortung für das Reich beanspruchten ${ }^{5}$.

Vor diesem Hintergrund erscheint es durchaus sinnvoll, nach dem Einsatz ritueller Unterwerfungen am Ende jener Konflikte Ausschau zu halten, die genau in demselben Zeitraum die Entwicklung der städtischen Autonomie begleiteten ${ }^{6}$. Dass solche Akte der Selbstdemütigung auch bei Auseinandersetzungen zwischen einem Stadtherrn und seiner aufrührerischen Stadt Anwendung fanden, ist dank der berühmten Unterwerfungen Mailands 1158 und 1162 vor Friedrich Barbarossa wohlbekannt ${ }^{7}$. Doch so berühmt die Mailänder Unterwerfungen auch sind, so wenig taugen sie doch zum Modell, vor allem wenn man den Blick auf die Städte nördlich der Alpen richtet. Denn hier traten weniger die Kaiser und Könige, sondern vor allem die Bischöfe im angesprochenen Zeitraum als Stadtherren auf, die sich mit den Autonomiebestrebungen der dort lebenden Bürger auseinandersetzen mussten ${ }^{8}$. Aber auch sie bedienten sich zuweilen dieses Mittels, wenn es galt, die Auseinandersetzungen mit ihren Städten beizulegen ${ }^{9}$. Insofern eröffnet sich hier ein Untersuchungsfeld, das es erlaubt, den Zusammenhang oder gar die Wechselwirkungen von Friedensstiftung und städtischer Autonomie zu erfassen. Um darüber erste Aussagen zu treffen, sollen im Folgenden drei städtische Unterwerfungen näher betrachtet werden. Gelten soll dabei die Aufmerksamkeit vor allem der Frage, wie und von wem sie ausgehandelt wurden, und dem Stellenwert, den die Selbstdemütigung der Bürger im Prozess der Konfliktbeilegung insgesamt besaß.

5 Vgl. J. Schlick, König, Fürsten und Reich 1056-1159. Herrschaftsverständnis im Wandel, Stuttgart 2001. Siehe auch G. Althoff, Die Macht..., S. 84.

6 Vgl. grundlegend K. Schulz, ,Denn sie lieben die Freiheit so sehr...'. Kommunale Aufstände und Entstehung des europäischen Bürgertums im Hochmittelalter, 2. Aufl., Darmstadt 1995.

7 Vgl. G. Althoff, Das Privileg..., S. 103-106; K. Görich, Die Ehre Barbarossas. Kommunikation, Konflikt und politisches Handeln im 12. Jahrhundert, Darmstadt 2001, S. 229ff. u. $249 \mathrm{ff}$.

8 Zur besonderen Stellung der Bischöfe als Stadtherrn vgl. E. Ennen, Bischof und mittelalterliche Stadt. Die Entwicklung in Oberitalien, Frankreich und Deutschland, [in:] Gesammelte Abhandlungen zum europäischen Städtewesen und zur rheinischen Geschichte, Bonn 1977, S. 40-52, S. 48ff.

9 Eingehender und vor allem mit Blick auf das spätere Mittelalter befassten sich C. Garnier, Zeichen und Schrift. Symbolisches Handeln und literale Fixierung am Beispiel von Friedensschlüssen im 13. Jahrhundert, „Frühmittelalterliche Studien“ 1998, Bd. 32, S. 263-287, und J.-M. Moeglin, Pénitence ..., S. 245-251, mit den rituellen Unterwerfungen von Adligen, aber auch von einzelnen Bürgern und Städten vor ihren Bischöfen. Die Unterwerfung der flandrischen Städte in burgundischen Zeit untersucht P. Arnade, Realms of Rituals. Burgundian Ceremony and Civic Life in Late Medieval Ghent, Ithaca-London 1996. 
Bemerkenswerterweise stand eine rituelle Unterwerfung auch im Zentrum der Bemühungen, den ersten großen städtischen Aufstand im römisch-deutschen Reich, die Erhebung der Kölner gegen Erzbischof Anno 1074 beizulegen ${ }^{10}$. Auslöser des Aufbegehrens war der Befehl Erzbischof Annos, ein Schiff im Hafen zu requirieren, um dem Bischof von Münster, mit dem er gemeinsam Ostern gefeiert hatte, den Heimweg zu erleichtern. Als die bischöflichen Dienstmannen zur Tat schreiten wollten, widersetzten sich die Leute des Eigentümers, eines angesehenen Kaufmanns. Dessen Sohn kam hinzu und hinderte mit Gleichgesinnten den Stadtvogt daran, zugunsten des Bischofs einzugreifen. Als der Metropolit die Widerspenstigen zur Verantwortung ziehen wollte, kam es zum Aufstand. Der Domschatz wurde geplündert, ein Mann im Dom getötet und der Erzbischof musste fliehen. Im Umland von Köln gelang es Anno ein Heer aufzubieten, mit dem er vor die Stadt zog. Von der Vielzahl der Krieger beeindruckt, nahmen die Aufständischen von einer militärischen Auseinandersetzung Abstand.

Nahezu alles, was man über diesen Konflikt weiß, verdankt man Lampert von Hersfeld ${ }^{11}$. Zwar beschreibt auch die Vita Annonis den Aufstand, doch übernimmt sie weithin den Text Lamperts wörtlich und bietet gerade mit Blick auf das Ende der Auseinandersetzung keine zusätzlichen Informationen ${ }^{12}$. Solche liefert immerhin ein Brief, den Anno von Köln selbst einige Wochen nach den Ereignissen an den Trierer Erzbischof Udo geschrieben hatte, um diesen vor den Machenschaften der von ihm im Verlauf des Konfliktes exkommunizierten Kölner Bürger zu warnen ${ }^{13}$. Allerdings beziehen sich seine spärlichen Aussagen vor allem auf die Exkommunikation und enthalten nur ein paar weiterführende Hinweise ${ }^{14}$. Somit ist und bleibt Lamperts Bericht die einzige Grundlage, von

${ }_{10}$ Vgl. hierzu und zum Folgenden die ausführliche Darstellung bei H. Stehkämper, Die Stadt Köln in der Salierzeit, [in:] Die Salierunddas Reich, Bd. 3: Gesellschaftlicherundideengeschichtlicher Wandel im Reich der Salier, hrsg. v. St. Weinfurter, 2. Aufl., Sigmaringen 1992, S. 75-152, bes. S. $93-$ 95. Siehe auch K. Schulz, op. cit., S. 75-99. Siehe auch K. Militzer, Der Aufstand der Kölner gegen Erzbischof Anno II. von 1074, [in:] In tempore belli et pacis. Ludzie-miejsca-przedmioty. Ksiega pamiatkowadedykowanaprof.dr.hab.JanowiSzymczakowiw65-lecieurodzini40-leciepracynaukowo-dydaktycznej, Warszawa 2011, S. 415-424, der die These zurückweist, der Erzbischof habe sich eines Rechtsbruches schuldig gemacht, und davon ausgeht, dass in dem Konflikt zwei verschiedene Rechtsauffassungen aufeinander gestoßen seien.

${ }_{11}$ Vgl. die Schilderung des Aufstandes und sein Ende bei Lampert von Hersfeld, Annales, hrsg. v. O. Holder-Egger, Hannover-Leipzig 1894, S. 185-193, 196f., 249f.

12 Siehe Vita Annonis archiepiscopi Coloniensis, hrsg. v. R. Köpke, Hannover 1854, S. 462 518. Zur Abhängigkeit der Vita von Lampert vgl. H. Stehkämper, Die Stadt..., S. 101 mit Anm. 112.

${ }^{13}$ Vgl. den Brief Annos, in: Die Hildesheimer Briefe, [in:] Die Briefsammlungen der Zeit Heinrichs $I V$., hrsg. v. C. Erdmann, N. Fickermann, Weimar 1950, Nr. 46, S. 90f. Datiert wird der Brief auf die Zeit nach dem 15. Juni 1074.

${ }^{14} \mathrm{Vgl}$. dazu im Folgenden, bei Anm. 26 bis 28. 
der man auszugehen hat, um sich ein Bild von den Vorgängen nach der Rückkehr Annos nach Köln zu machen.

Lamperts Worten zufolge schickten die Kölner beim Anblick des Heeres dem Erzbischof „Gesandte wegen des Friedens entgegen, bekannten sich schuldig und erklärten sich bereit, jede Strafe auf sich zu nehmen, sofern ihr Leben geschont werde" ${ }^{\text {"15. }}$. Daraufhin soll ihnen der Erzbischof Vergebung versprochen haben, vorausgesetzt, sie zeigten aufrichtig Reue. Mit diesen Worten hatte Lampert jedem Leser vor Augen geführt, dass der Bischof den Konflikt mit einer rituellen Unterwerfung beenden wollte, wie sie damals Usus war ${ }^{16}$. Und in der Tat entspricht dann seine Schilderung der nachfolgenden Ereignisse genau den damaligen Gepflogenheiten:

Nach der Feier des Hochamtes zu St. Georg lud er [sc. der Erzbischof] dann alle diejenigen, die den Bischof von seinem Besitz vertrieben, die die Kirche durch Mord befleckt, die die Kirche des hl. Petrus [d.h. der Dom] feindlich angegriffen und die sonstigen Rechte der Kirche durch barbarische Schandtat verletzt hatten, durch bischöflichen Bann zur Genugtuung vor. Alsbald zogen sie alle barfuß mit wollenen Gewändern auf dem bloßen Leibe heran, nachdem sie mit Mühe und Not von den (vielen) Leuten, die den Erzbischof umgaben, die Zusicherung erhalten hatten, dass sie das ohne Gefahr tun könnten ${ }^{17}$.

Doch das genügte dem Kölner Bischof nicht. Er wies die Bürger an, sich am nächsten Tag im Dom einzufinden, wo er ihnen nach den kanonischen Vorschriften eine Kirchenbuße auferlegen wollte ${ }^{18}$.

Die Kölner, von denen mehrere Hundert schon in der Nacht geflohen waren, kamen aber nicht. Und als sie auch am dritten Tag nicht zu sehen waren, konnten sich nach Lampert die Krieger des Bischofs nicht mehr zurückhalten und fielen mit Gewalt über die Bürger her ${ }^{19}$. Wie und wann anschließend die Schuldigen zur

15 „Quod ubi Coloniensibus compertum [...]; magno terrore concussi obviam legatos de pace miserunt, se reos confitentes et omnem, quam vita incolumi iuberentur paenam pendere paratos". (Lampert von Hersfeld, op. cit., ad 1074, S. 191. Übers. teils nach der Freiherr von Stein-Gedächtnisausgabe 13, S. 247.

${ }^{16}$ Cf. G. Althoff, Das Privileg..., S. 100f.; idem, Die Macht ..., S. 77 u. 84.

17 „Tum celebrata missarum solemnitate apud Sanctum Greorgium, eos qui pontificem sede propria expulissent, qui aecclesiam homicidio polluissent, qui templum sancti Petri hostiliter impetissent, qui caetera religionis iura ausu barbaro temerassent, episcopali banno ad satisfactionem vocavit. Protinus omnes nudis pedibus, laneis ad carnem induti processerunt, vix et aegre impetrata pace multitudinis, quae circa episcopum erat, ut hoc tuto facere sinerentur. Nam et vehementer ei succensebant, quod, dum inmoderatius clementiam ostentando popularis fieri vellet, nefarios homines ad audenda nequiora huius sceleris impunitate animaret". Lampert von Hersfeld, op. cit., ad 1074, S. 191.

${ }_{18}$ Vgl. ibidem, S. 191f.: „Archiepiscopus eos postero die ad suscipiendam secundum canonum scita penitentiam tam inmanis flagicii ad Sanctum Petrum presto esse iubet”.

${ }^{19}$ Cf. ibidem, S. 192: „Unde indignitatem rei non ferentes episcopi milites, inscio, ut plurimi asserunt, atque inconsulto archiepiscopo, arma rapiunt, domos incursant, possessiones diripiunt, 
Verantwortung gezogen wurden, lässt der Mönch aus Hersfeld offen. Am Ende wurden der Sohn des Kaufmanns und ein paar weitere Aufständische geblendet, einige gestäupt und geschoren und viele mit Vermögensbußen gestraft. Zu guter Letzt mussten die Kölner beeiden, ,dass sie in Zukunft die Stadt so gut sie mit Rat und Tat vermöchten, für den Erzbischof gegen jedermanns Gewalttätigkeit verteidigen [...] würden“20. Und sie mussten versprechen, diejenigen, die in der Nacht zuvor die Stadt verlassen hatten, solange als Feinde zu betrachten, bis diese eine gebührende Genugtuung geleistet hätten ${ }^{21}$. So berichtet es Lampert von Hersfeld.

Was der Hersfelder Mönch, der den Kölner Erzbischof kannte und verehrte, mit seiner Schilderung verfolgte, ist offensichtlich ${ }^{22}$. Ihm ging es darum, das Ansehen des Bischofs, das unter den Kölner Ereignissen gelitten hatte, wiederherzustellen. Das kann man indirekt auch seinen Ausführungen selbst entnehmen. Denjenigen gegenüber, die nach seinen Worten den Bischof für die Übergriffe seiner Dienstleute nach der Unterwerfung verantwortlich machten, weist er darauf hin, dass die meisten nicht dieser Ansicht seien, ganz abgesehen davon, dass die Bürger nur eine verdiente Strafe für ihr maßloses Tun erhalten hätten ${ }^{23}$. Darüber hinaus schildert er in einigem Abstand zum Jahr 1075, als er über die letzten Tage Annos berichtet, eine Vision, die dem Bischof etwa ein halbes Jahr vor dessen Tod zuteilwurde ${ }^{24}$. Der Bischof habe mit ansehen müssen, wie ihm im Jenseits der Platz in einer Runde illustrer Bischöfe versagt wurde, weil

occursantes partim sternunt, partim captos in vincula coniciunt, et prorsus, ut veritati vel coacto assentiamur, multo ferocius, quam tanti pontificis existimationi competeret, iustae ultionis negocium exsequuntur. Sed gravior morbus acriori indigebat antidoto“.

${ }^{20}$ Cf. ibidem: „Filius supramemorati mercatoris, qui primus sedicione inflammaverat populum, et pauci alii luminibus sunt orbati, nonnulli virgis cesi ac detonsi, omnes gravissimo rei familiaris damno multati atque iusiurandum dare compulsi, quod deinceps archiepiscopo civitatem contra omnium hominum violentiam, quantum consilio et armis possent, vindicaturi essent $[\ldots]$ ].

${ }^{21},[\ldots]$ et eos qui ex urbe profugerant, quoad digne archiepiscopo satisfecissent, semper pro infestissimis hostibus habituri". Ibidem.

${ }^{22} \mathrm{Zu}$ den Beziehungen Lamperts zu Anno vgl. D. Lück, Erzbischof Anno II. von Köln. Standesverhältnisse, verwandtschaftliche Beziehungen und Werdegang bis zur Bischofsweihe, „Annalen des Historischen Vereins für den Niederrhein“ 1970, Bd. 172, S. 7-112, S. 69, und U. Neddermeyer, Aufstand gegen den Erzbischof 1074: Lampert von Hersfeld berichtet, [in:] Quellen zur Geschichte der Stadt Köln, Bd. 1: Antike und Mittelalter. Von den Anfängen bis 1396/97, hrsg. v. W. Rosen, L. Wirthler, Köln 1999, S. 109-132, 110, und zuletzt C. Zey, Vormünder und Berater Heinrichs IV. im Urteil der Zeitgenossen (1056-1075), [in:] Heinrich IV., hrsg. v. G. Althoff, Ostfildern 2009, S. 87-125, S. 94, die es zwar auch für möglich, aber nicht für zu beweisen hält, dass Lampert ein Schüler Annos im Bamberg war. Auf die Probleme, die Lamperts rhetorisch ausgefeilter Bericht, mit sich bringt, wies schon G. Meyer von Knonau, Jahrbücher des deutschen Reiches unter Heinrich IV. und Heinrich V., Bd. 2, Leipzig 1890, S. 804ff. hin, der dennoch davon ausgeht, dass Lampert die Vorgänge im Kern richtig wiedergibt (ibidem, S. 392, Anm. 112).

${ }^{23} \mathrm{Vgl}$. das Zitat in Anm. 19.

${ }^{24}$ Vgl. hierzu und zum Folgenden Lampert von Hersfeld, op. cit., ad 1075, S. 248f. 
ein schwarzer Fleck sein weißes Kleid beschmutzte. Dieser Makel, so erfährt es dann der Leser, sei aber nichts anderes als ein Hinweis auf die harte Behandlung der Kölner Bürger, denen der Bischof immer noch nicht vergeben habe. Genau das aber tut der Bischof, nachdem ihm ein Begleiter den Sinn der Vision offenbart hatte. Dass Lampert diese Geschichte bei der Gesamtwürdigung Annos glaubte einfließen lassen zu müssen, offenbart, wie sehr die gewalttätigen Ereignisse nach der Unterwerfung der Kölner Bürger die Reputation des Erzbischofs als geistlichem Würdenträger beschädigt hatten.

Um dem entgegenzuwirken, spricht Lampert in seiner Darstellung den Bischof von aller Schuld an den gewalttägigen Exzessen frei und hebt dessen Bemühen um Versöhnung hervor. Umgekehrt macht er die Städter, weil sie sich dem Urteil des Bischofs nicht stellten, für das Scheitern der anvisierten Konfliktbeilegung verantwortlich. Diese eindeutige Schuldzuweisung führt zwangsläufig zu der Frage, was man dem Bericht überhaupt entnehmen kann - eine Frage, die sich oft bei Lampert stellt ${ }^{25}$. Am Vollzug der rituellen Unterwerfung wird man jedoch kaum zweifeln. Was Lampert hier schildert, entspricht auch anderweitig verbürgten Gepflogenheiten solcher Akte ${ }^{26}$. Das Aufsehen, das der Kölner Aufstand im Reich erregte $^{27}$, verbot es Lampert zudem hier einfach eine deditio zu erfinden.

Für die anschließende Behauptung, der Bischof hätte die Bürger am Tag nach der Unterwerfung aufgefordert, die Kirchenbußen entgegenzunehmen ${ }^{28}$, gilt das schon weniger. Sie verträgt sich bestens mit seiner Absicht, eine weltliche Bestrafung der Rädelsführer gar nicht im Sinne des Erzbischofs erscheinen zu lassen. Und was Lampert wiedergibt, ist bloß eine reine Absichtserklärung, deren Realitätsgehalt bereits die Zeitgenossen nicht überprüfen konnten, weil es dazu auch de facto nicht gekommen ist. Zweifel kommen aber auch auf, weil in anderen Fällen, in denen Kirchenstrafen ausgesprochen wurden, die Bischöfe die Betroffenen zuvor exkommuniziert hatten ${ }^{29}$. Dazu ist in Köln allerdings nicht gekommen, wie man dem Brief Annos entnehmen kann. Er nämlich schreibt

${ }^{25}$ Vgl. zur Einschätzung Lamperts R. Schieffer, Art. Lampert von Hersfeld, [in:] Die deutsche Literatur des Mittelalters. Verfasserlexikon, Bd. 5, Berlin-New York 1985, S. 513520. Zu seiner Schwarz-Weiß-Malerei bei der Darstellung von Konflikten siehe auch H. Vollrath, Konfliktwahrnehmung und Konfliktdarstellung in erzählenden Quellen des 11. Jahrhunderts, [in:] Die Salier und das Reich..., S. 279-296, bes. 289-290.

${ }^{26} \mathrm{Vgl}$. zu den Formen solcher Unterwerfungen und den kirchlichen Bußformen, aus denen sie erwachsen sind, K. Schreiner, ,Nudis pedibus'. Barfüßigkeit als religiöses und politisches Mittel, [in:] Formen und Funktionen öffentlicher Kommunikation im Mittelalter, hrsg. v. G. Althoff, Stuttgart 2001, S. 53-124, und zum hier besprochenen Fall, S. 74f., sowie G. Althoff, Das Privileg..., S. $100 \mathrm{ff}$. und J.-M. Moeglin, Pénitence..., S. 243 u. 250f.

27 Vgl. den Brief Annos, in dem er davon spricht, dass sich die Kunde von dem Aufstand auch ohne seinen Brief bestimmt bis nach Trier herumgesprochen habe (Die Hildesheimer Briefe, S. 90).

${ }^{28} \mathrm{Vgl}$. oben das Zitat in Anm. 18.

29 Vgl. H. Kamp, op. cit., S. 137 u. 142. 
davon, dass er zwar die Bürger nach seiner Flucht habe bannen wollen, dann aber aus Nachsicht davon abgesehen habe. Insofern ging der Unterwerfung in Köln keine Exkommunikation voraus, was die Darstellung Lamperts nicht gerade stützt. Anderes kommt hinzu.

So bannte Anno nach eigener Auskunft die Kölner dann einige Wochen später, weil sie sich seinem Urteil entzogen hatten ${ }^{30}$. Davon sagt Lampert zunächst einmal nichts. Bei ihm reagiert der Kölner Erzbischof auf das Nicht-Erscheinen der Bürger entspannt. Nun ist bei Lampert nicht einmal mehr von Kirchenstrafen, die der Erzbischof verhängen wollte, die Rede. Vielmehr wartet der Bischof auf das Kommen derjenigen, die nicht die Stadt verlassen hatten, und auf deren Vorschläge ,zu irgendeiner Genugtuung ${ }^{‘ 31}$. Jetzt heißt es wieder wie zu Beginn der Unterwerfungsszene satisfactio statt paenitientia. Sogar vom Anspruch des Erzbischofs, selbst die Bußen festzulegen, ist plötzlich nicht mehr die Rede, so als ob die anschließend beschriebenen Gewaltakte der bischöflichen Dienstmannen mit dem Bischof in Verbindung gebracht werden könnten, wenn man ihn als strafenden Bischofs darstellt. Dementsprechend schweigt sich Lampert dann über die Exkommunikation der Kölner durch Anno aus und berichtet zur Überraschung seiner Leser ein paar Seiten weiter, Heinrich IV. habe Anno bei einem Treffen gebeten, den Kölnern zu verzeihen und sie wieder in die Kirche aufzunehmen, was dieser abgelehnt habe ${ }^{32}$. Dass es Anno aber nicht nur bei der Exkommunikation belassen hatte, erfährt man dann in den Einträgen zu 1075, wo davon die Rede ist, dass Anno kurz vor seinem Tod die Kölner auf Fürsprache eines Vertrauten nicht nur vom Bann löste, sondern ihnen auch ihr konfisziertes Vermögen zurückgab ${ }^{33}$. Insofern scheint der Hersfelder Mönch bei der Schilderung ganz bewusst auf jeden Hinweis auf

${ }^{30}$ „Abhominabilem vero temeritatem illorum licet eadem die secundum statuta canonum anathematis mucrone punire debuerim, iudicii tamen districtionem velociter exhibere sustinui, ne proprio satisfacere viderer zelo et non Domini. Sed quia compatientis animum contempsit quẹdam pars insolentium et nocturnis se temporibus furtim subtraxerunt, graviora minantes quam fecerint, consilio episcoporum, quos apostolicus direxit ad nos, in octavis eos pentecostes anathematizavi“. Die Hildesheimer Briefe, S. 90.

31 „Caeteri ingresso archiepiscopo civitatem et toto triduo iuxta condictum expectanti e minime se presentaverunt ad proponendum aliquod satisfactionis genus". Lampert von Hersfeld, op. cit., ad 1074, S. 192.

32 Vgl. ibidem, S. 196.

${ }^{33}$ Vgl. ibidem, ad 1075, S. 249f.: ,[...] statimque destinatis circumquaque nunciis cives a omnes Coloniae, quos in ultionem iniuriae suae excommunicatos urbe fugaverat, ad se evocavit, eisque proxima festivitate paschali - nam in quadragesima visionem viderat - non solum communionem aecclesiasticam, sed etiam bona sua omnia, quae direpta fuerant, benignissime restituit". Lampert selbst bringt die Bannung der Kölner zum ersten Mal für den Leser etwas unvermutet anlässlich der nur von ihm beschriebenen Zusammenkunft Heinrichs IV. mit Anno zur Sprache, wo der König den Erzbischof aufgefordert haben soll, die Exkommunikation zurückzunehmen. Vgl. ibidem, S. 196, und dazu G. Jenal, Erzbischof Anno II. von Köln und sein politisches Wirken. Ein Beitrag zur Geschichte der Reichs- und Territorialpolitik im 11. Jahrhundert, 2 Bde., Stuttgart 1974, Bd. 2, S. 383 u. 397. 
irgendwelche tatsächlichen Strafaktionen des Bischofs verzichtet zu haben, um ja den Eindruck zu vermeiden, Anno hätte etwas mit dem Vorgehen seiner Dienstmannen nach der gescheiterten deditio zu tun. Zugleich lässt diese Darstellungsweise den Verdacht entstehen, Anno habe sehr wohl etwas mit der Bestrafung der Aufständischen tun, zumal dieser ja nach den Worten der Hersfelder Mönchs auch später keine Scheu zeigt, das Vermögen der geflohenen Bürger zu konfiszieren ${ }^{34}$. Dieser Vermutung leistet Lampert Vorschub, indem er am Ende seines Berichtes geschickt offenlässt, wer für das Strafgericht verantwortlich zeichnet. Denn nachdem er die Gewaltexzesse in der Stadt den erzürnten bischöflichen Dienstmannen zugeschrieben hat, wird die Bestrafung der Kölner Bürger nur im Passiv geschildert ${ }^{35}$.

Auch wenn sich folglich Vorbehalte gegen Lamperts Version geltend machen lassen, so sprechen einige Indizien durchaus für seine Aussage, der Bischof habe den Konflikt zunächst mit einer kirchlichen Buße beilegen wollen. So stellt Anno in seinem Brief sein eigenes Vorgehen ähnlich dar, als er davon spricht, er habe die Kölner zunächst exkommunizieren wollen. Von daher mag der Bischof grundsätzlich erst einmal an kirchliche Strafen und an eineArt Kirchenbuße gedacht haben, zumal auch die inkriminierten Vergehen Kirchenstrafen nahelegten ${ }^{36}$. Und da sich die Vorstellungen und Praktiken von Exkommunikation und öffentlicher Kirchenbuße im 11. Jahrhundert noch vielfach überlappten ${ }^{37}$, wird Lampert doch nicht unbedingt falsch liegen, wenn er Anno nach der deditio Kirchenstrafen ankündigen lässt.

Noch wichtiger für ein angemessenes Verständnis der Vorgänge ist möglicherweise etwas anderes: die Flucht unzähliger Bürger noch in der Nacht, bevor der Bischof ihnen nach Lampert die kirchlichen Bußen auferlegen wollte ${ }^{38}$. $\mathrm{Zu}$ erklären ist dieses Verhalten nur, wenn man davon ausgeht, dass die Städter von der Anweisung des Bischofs überrascht waren, der ihnen zusätzlich zur Unterwerfung noch Strafen auferlegen wollte. Zwar gab eine rituelle Unterwerfung dem Herrn das Recht zu einer anschließenden Bestrafung, aber sie konnte auch für sich selbst schon die Genugtuungsleistung darstellen ${ }^{39}$. Vielleicht aber

${ }^{34} \mathrm{Vgl}$. das Zitat in den vorhergehenden Anm.

${ }^{35}$ Vgl. das Zitat in Anm. 20.

${ }^{36}$ Vgl. Lampert von Hersfeld, op. cit., ad 1074, S. 191-192, mit den Zitaten in den Anm. 17 u. 18. Vgl. dazu auch H. Stehkämper, Die Stadt..., S. 96, der davon ausgeht, dass der Bischof bewusst die Entsühnung nach Kirchenrecht, und nicht nach weltlichem Recht vollziehen wollte, und darauf verweist, dass von Lampert bei der Schilderung der deditio nur von Vergehen gegen das kirchliche Recht, sprich Vertreibung des Bischofs, Mord in einer Kirche und Angriff auf den Dom, genannt werden. Dass Lampert genau dieses Bild schaffen wollte, ist unbestritten, ob es aber dem Ablauf der Ereignisse in Köln entspricht, dann doch wieder fraglich.

${ }^{37}$ Vgl. J.-M. Moeglin, Pénitence..., S. 238ff.

${ }_{38}$ Diese Flucht thematisiert auch der Brief Annos. Cf. das Zitat in Anm. 30.

${ }^{39}$ Schon ein paar Zeilen früher weist Lampert den Leser darauf hin, dass es dem Bischof darum gehen wird, Genugtuung für die Schmach zu erhalten. So lässt er, um die Opferbereitschaft 
hatten die Bürger auch nur Angst, über die Maßen bestraft zu werden. Wie dem auch sei, in jedem Fall waren die Kölner Bürger offenkundig über das, was passieren sollte, im Unklaren gelassen worden. Und das hängt wohl ursächlich mit der Form der Konfliktbeilegung zusammen, die ohne Vermittler oder Fürsprecher erfolgte.

Lampert selbst spricht von Boten oder Gesandten, die an den Bischof geschickt wurden, um Frieden zu erbitten ${ }^{40}$. Um wen es sich handelte, sagt er nicht. Aber die Kölner Aufständischen werden wie üblich auf Personen zurückgegriffen haben, die zumindest in der Umgebung des Erzbischofs, wenn auch vielleicht nicht bei diesem selbst, Gehör finden konnten. Diese hatten sich mit Sicherheit nicht an vorderster Front an der Erhebung beteiligt. Nach dem üblichen Procedere dürften dann die Leute des Bischofs diesen Boten mitgeteilt haben, dass nur eine demütige Unterwerfung den aufständischen Bürgern das Leben retten könne, wie dies auch in anderen Fällen geschah ${ }^{41}$. Dabei haben sie ihnen wohl auch die Zusage gemacht, dass die Bürger mit der Unterwerfung der Gefahr für Leib und Leben entkommen würden ${ }^{42}$. Doch mehr werden sie ihnen nicht versprochen haben. Lampert selbst jedenfalls berichtet nichts davon, obschon er in anderen Fällen weitergehende Versprechungen erwähnt ${ }^{43}$. Es gab also nicht mehr als bilaterale Verhandlungen, niemand hatte es auf sich genommen, den Bischof auf ein bestimmtes Verhalten nach der Unterwerfung zu verpflichten. Und so wussten die Städter auch nicht, ob und in welchem Maß der Bischof das aus der deditio erwachsene Recht, mit den Unterworfenen zu tun, was er wolle, nutzen würde. Indem er dann aber ein Verdikt unmittelbar nach der Unterwerfung ankündigte, überraschte er ganz offenbar viele Bürger oder bestätigte sie in ihrer negativen Einschätzung, weshalb sich die Betroffenen den drohenden Strafen durch Flucht entzogen.

und übermäßige Einsatzfreude der vom Bischof rekrutierten Krieger dem Leser vor Augen führten, diese sagen, sie würden, wenn „,die Kölner [...] dem Bischof nach seinem Ermessen für die Kränkung keine Genugtuung leisten würden, [...] die Bewohner mitsamt der Stadt verbrennen lassen [...] und ihn über Haufen von Erschlagenen auf seinen Bischofsstuhl zurückführen“ („Quod nisi Colonienses maturent venientem suscipere et pro ipsius arbitratu satisfacere offenso, se aut ingesto igne populum cum civitate consumpturos, aut dissipate muro eum super congeriem occisorum in cathedram pontificalem reducturos”). Lampert von Hersfeld, op. cit., ad 1074, S. 191.

40 Siehe oben Anm. 15.

${ }^{41} \mathrm{Zu}$ den Usancen vgl. G. Althoff, Das Privileg..., S. 100-101 u. 118; H. Kamp, op. cit., S. 167, 193-196.

${ }^{42}$ Dies geht zum einen aus der Bitte der Kölner um Unterwerfung und zum anderen aus der Beschreibung der Unterwerfung indirekt hervor: „[...] se [sc. die Kölner] reos confitentes et omnem, quam vita incolumi iuberentur paenam pendere paratos... Protinus omnes nudis pedibus, laneis ad carnem induti processerunt, vix et aegre impetrata pace multitudinis, quae circa episcopum erat, ut hoc tuto facere sinerentur“. Lampert von Hersfeld, op. cit., ad 1074, S. 191.

${ }^{43}$ So zum Beispiel im Zusammenhang der Unterwerfung von Spier 1075 (ibidem, ad 1075, S. 237). Siehe dazu auch H. Kamp, op. cit., S. $169 f$. 
Dass in diesem Konflikt keine Vermittler auftraten, dürfte mit dem Fehlen politisch belastbarer Beziehungen zwischen den Bewohnern der Stadt und dem Adel sowie den Ministerialen im Umfeld des Bischofs zusammenhängen. Dafür scheint in jener Zeit, obschon es bereits eine vermögende Oberschicht in Köln gab, das soziale Gefälle noch zu groß gewesen $\operatorname{sein}^{44}$. Darüber hinaus mangelte es an Organen und Institutionen, die es erlaubt hätten, die Stadt als Kollektiv $\mathrm{zu}$ behandeln und ihr gegenüber bestimmte Verpflichtungen einzugehen. Das bezeugen auch die anschließenden Strafaktionen, bei denen wie erwähnt immer nur einzelne zur Verantwortung gezogen wurden.

Gerade weil eine städtische Autonomie in diesen Jahrzehnten noch $\mathrm{Zu}$ kunftsmusik darstellte und das soziale Prestige der Bürger in der Welt der Führungsschichten gering war, erweist sich die in Köln gewählte Form der Konfliktbeilegung für die Städter als problematisch. Es war allein der Bischof, der von ihr profitierte. Er führte den Bürger seine stadtherrliche Gewalt vor Augen, indem er ihnen befahl, in demütigen Aufzug vor die Stadt zu kommen. Vor allem aber stand es ihm nach der Selbstübergabe der Bürger frei, diese nach seinem Dafürhalten zu bestrafen, zumal alle Bürger, die sich unterworfen hatten, ein Schuldgeständnis abgelegt hatten. Möglicherweise ergibt sich aus dieser Perspektive noch ein Grund, weniger an Lamperts Erzählung zu zweifeln, nach der der Bischof nach Kirchenrecht Kirchenbußen habe verhängen wollen. Denn mit einem solchen Vorgehen hätte er alle Bewohner als Sünder ohne Hinsicht auf ihren unterschiedlichen Rechtsstatus zur Verantwortung ziehen können. Sollte es ihm darum gegangen sein, so hätte man in der Unterwerfung primär einen kirchlichen Bußakt zu sehen.

Wie dem auch sei, in jedem Fall entfaltete die Unterwerfung eine politische Wirkung. Sie schuf das Bild einer (kirchen-)rechtlich homogenen Bürgerschaft in der Öffentlichkeit, das später durch den gemeinsamen Eid bestätigt wurde. Damit aber trug die besonders erniedrigende Unterwerfung der Kölner, wenn auch ungewollt dazu bei, dass sich die Städter als rechtliche Gemeinschaft sehen und begreifen konnten.

II.

Waren in Köln wie auch anderswo die Formen städtischer Autonomie um 1075 so gut wie gar nicht entwickelt, so änderte sich dies seit Beginn des 12. Jahrhunderts. Immer häufiger stellten nun die Könige, aber auch die bischöflichen oder landesherrlichen Stadtherren den Bürgern Privilegien aus. Die Eigenständig-

${ }^{44}$ Cf. Lampert von Herfeld, op. cit., ad 1074, S. 186 u. 187, der wiederholt von den Ersten oder den Vornehmen (primores) der Stadt spricht, die offenkundig auch untereinander verheiratet waren. Vgl. zum Kölner Meliorat im 11. Jahrhundert H. Stehkämper, Die Stadt..., S. 111-114. 
keit der Städte und Bürgergemeinden wuchs dann besonders in den Auseinandersetzungen des Thronstreits von 1198, als die jeweiligen Könige und Fürsten um Unterstützung buhlten. In der Folge bildeten sich immer häufiger städtische Ratsgremien, die nun im Namen der Stadt handeln konnten. So tritt man denn auch 1198 in Speyer und Worms, 1201 in Lübeck, um 1212 in Erfurt, 1213 in Soest, 1216 in Köln auf solche Institutionen, die sich im Verlauf des 13. Jahrhunderts immer mehr ausbreiteten ${ }^{45}$. Das gilt auch für die Bischofsstadt Paderborn, wo der Rat 1238 das erste Mal Erwähnung fand ${ }^{46}$. Die dortigen Autonomiebestrebungen erhielten nicht zuletzt durch einen Konflikt Auftrieb, der mit einer rituellen Unterwerfung beigelegt wurde ${ }^{47}$. Die eigentliche Auseinandersetzung wird nirgends beschrieben; die einzige Quelle, die festhält, wie der Streit gelöst werden sollte, ist eine Urkunde vom 22. April $1222^{48}$.

Die Entscheidung der Paderborner Bürger, vor ihrem Bischof die Stadttore zu schließen und ihm so den Eintritt in seine Stadt zu versperren, bildete den Anlass für die Auseinandersetzung. Der Bischof fühlte sich in seiner Ehre verletzt, und zwar umso mehr, als er angab, die Bürger hätten ihn schon länger in seinen Rechten beeinträchtigt ${ }^{49}$. Ob es zu weiteren Gewalttätigkeiten kam, ist unbekannt. Anders als im Kölner Konflikt von 1074 traten bald Vermittler auf, die nach einer Lösung suchten und mit Hilfe eines weiteren Schlichters eine compositio vorlegten, die den Fahrplan für die Beilegung des Streits festschrieb und Gegenstand der genannten Urkunde ist. Hier in Paderborn kam es also zu einer Abmachung zwischen den Konfliktparteien, für die die eigens genannten Vermittler einstanden. Auch wenn das gewählte Verfahren mit der Berufung von vier Personen, die mit Hilfe eines Obmannes eine bindende schriftliche Vereinbarung vorlegen, an die seit dem 12. Jahrhundert aufkommende Schiedsgerichtsbarkeit erinnert, so hat man es doch

${ }^{45}$ Vgl. E. Isenmann, Die deutsche Stadt im Mittelalter 1150-1550: Stadtgestalt, Recht, Verfassung, Stadtregiment, Kirche, Gesellschaft, Wirtschaft, Köln-Weimar 2014, S. 216-217.

${ }^{46}$ Zur Entwicklung in Paderborn vgl. M. Becher, Zwischen Reichspolitik und regionaler Orientierung: Paderborn im Hochmittelalter (1050-1200), [in:] Paderborn. Geschichte der Stadt in ihrer Region, Bd. 1: Das Mittelalter. Bischofsherrschaft und Stadtgemeinde, hrsg. v. J. Jarnut, Paderborn 2000, S. 121-196, bes. 190-195, und H. Schoppmeyer, Die spätmittelalterliche Bürgerstadt (1200-1600), [in:] Paderborn. Geschichte der Stadt..., S. 199-473, bes. 226-240.

${ }^{47}$ Vgl. S. Käuper, Aufstand und Kommunebildung im 13. Jahrhundert. Zwei Fälle aus Paderborn, [in:] Bischof und Bürger. Herrschaftsbeziehungen in den Kathedralstädten des Hochund Spätmittelalters, hrsg. v. U. Grieme, N. Kruppa, S. Pätzold, Göttingen 2004, S. 27-66, bes. 33-44, u. H. Schoppmeyer, op. cit., S. 229-232.

48 Vgl. Westfälisches Urkundenbuch, Bd. 4: Die Urkunden des Bisthums Paderborn vom J. 1201-1300, Erste Abteilung: Die Urkunden der Jahre 1201-1240, bearb. von R. Wilmans, Münster 1874 ND Osnabrück 1973, Nr. 99, S. 69.

49 „Notum sit omnibus [...] quod cum dominus episcopus Patherbrunensis gravis animi esset contra cives Patherbrunenses pro eo, quod portas civitatis in dedecus suum preclusissent ad inferendam sibi et suis violenciam, ut asseruit, insuper et ab antiquo in multis eos molestasse proponeret [...]" (ibidem). 
mit einer Form der Vermittlung zu tun ${ }^{50}$. Zum einen ist nämlich in der Urkunde nur von Vermittlern die Rede, zu denen auch namenlose bischöfliche Ministerialen gezählt werden. Zum zweiten werden die namentlich genannten Personen, die alle dem Domkapitel entstammten, nicht einer der Parteien zugeordnet ${ }^{51}$. Zum dritten besaß auch der Scholaster Johannes von Xanten, dessen Stellung an die eines Obmanns erinnert, keine richterlichen Befugnisse, sondern sollte die anderen Friedensstifter bei ihrem Bemühen bloß unterstützen. Und schließlich stand am Ende des Verfahrens kein Schiedsurteil, zu dessen Einhaltung sich die Parteien vorab verpflichtet hätten, sondern eine einvernehmliche Übereinkunft, der sie zustimmten, indem sie die Urkunde besiegelten ${ }^{52}$.

Für eine Versöhnung mit den Bürgern der Stadt stellte der Paderborner Bischof zwei Vorbedingungen. Zunächst einmal sollten 500 Bürger vor die Stadt zum bischöflichen Haupthof Enehus kommen, von dort mit nackten Füßen und leinenem Gewand bis zum Westerntor ziehen und dann durch die Hauptstraße bis zum bischöflichen Palast gehen. Hier sollten sie seine Gnade erbitten, damit er sich wiederum bereit erkläre, ihre Entschuldigung zu empfangen ${ }^{53}$. Zuvor sollten die Bürger allerdings noch einen Mann namens Gerlach wieder der Gewalt des

${ }^{50}$ Vgl. hierzu und zum Folgenden: ,[...] mediantibus maiore decano, [sic!] J. preposito sancti Petri $\mathrm{H}$. et V. de Sualenberg et V. cellerario et pluribus ecclesie ministerialibus, pro posse me collaborante, ut futuris malis caveretur, hec intervenit compositio: [...]" (ibidem). Zur Schiedsgerichtsbarkeit cf. H. Kamp, op. cit., S. 240-242.

51 Während S. Käuper (op. cit., S. 36) und H. Schoppmeyer (op. cit., S. 230) Schwierigkeiten haben, die Vermittler sinnvoll zu identifizieren, lösen sich diese auf, wenn man den Emendata in den Nachträgen der Edition (Westfälisches Urkundenbuch, Bd. 4: Die Urkunden des Bisthums Paderborn vom J. 1201-1300, Dritte Abteilung: Die Urkunden der Jahre 1251-1300, bearb. von H. Finke, Personen- und Ortsregister bearb. von H. Hoogeweg, Münster 1894, S. 1201) folgt. Denn dann steht das Komma in der oben (Anm. 48) zitierten Passage nicht hinter „decano“, sondern hinter „J.“, so dass das Kürzel auf den Domdekan und nicht auf den Propst des Petersstiftes (Busdorfstift) zu beziehen ist, dessen Name wiederum nach der neuen Lesart mit H. abgekürzt wird. Damit passen die Kürzel bestens zu den damals nachzuweisenden Amtsträgern (S. Käuper, op. cit., S. 36, Anm. 55), nämlich dem Domdekan Johannes und dem damaligen Propst des Busdorfstiftes Heinrich. Infolgedessen finden sich auch nicht mehr zwei Schwalenberger unter den Vermittlern, sondern nur noch einer, nämlich Folkuin. Als letzter erscheint der Kellermeister Volbert des Domstifts, den man identifizieren kann, da alle genannten Personen im Herbst desselben Jahres als Zeugen in einer Urkunde vollständig genannt und zudem als Kanoniker des Domes bezeichnet. Vgl. Westfälisches Urkundenbuch, Bd. 4, Nr. 101, S. 71. Auch in der Urkunde ist der Scholaster Johannes genannt, was Anlass gibt, ihn mit dem Scholaster Johannes von Xanten zu identifizieren.

52 „Sicut autem rogatus fui hec conscribere pro bono communi sic, ut firmius serventur in posterum, placuit omnibus scriptum hoc domini episcopi ecclesie et civitatis sigillis communiri" (ibidem, Nr. 99, S. 69). Vgl. H. Schoppmeyer, op. cit., S. 232-233 zur Entwicklung des Paderborner Siegels.

${ }^{53}$ „Ut de civibus quingenti nudis pedibus et in laneis de loco, qui dicitur Sola domus per portam occidentalem usque ad palacium episcopi procedentes gratiam suam, ut moris est, quererent, quatinus expurgationem super innocentia sua, quam offerebant, recipere dignaretur [...]" (Westfälisches Urkundenbuch, Bd. 4, Nr. 99, S. 69). 
Bischofs überantworten. Erst danach wollte der Bischof die von jedem einzeln dargebrachte Entschuldigung annehmen ${ }^{54}$. Die volle Gnade aber sollten die Bürger erst nach der Zahlung von 100 Mark Silber finden, wodurch auch ihre bisherigen Rechtsbrüche gesühnt sein sollten ${ }^{55}$.

Trotz der symbolischen Anleihen bei der Kirchenbuße erscheint hier in Paderborn die rituelle Unterwerfung weniger als religiöser Akt. Sie gleicht vor allem einem Schandaufzug in der Tradition der Harmschar, obgleich in diesem Fall die Beteiligten keine schandhaften Objekte tragen müssen, wie dies ansonsten der Fall war ${ }^{56}$. Um den Ehrverlust, den die Bürger ihrem Bischof mit der Schließung der Tore bereitet hatten, wiedergutzumachen, mussten sie sich selbst demütigen und auf alle Zeichen ihres Standes verzichten. Nur so vermochten sie die Huld des Stadtherrn wiederzufinden, die sie vollständig erhalten sollten, sobald sie den besagten Mann dem Bischof restituiert und die Geldbuße gezahlt hatten. Die Bedeutung der Unterwerfung erschließt sich aber erst, wenn man sie im Spiegel der weiteren rechtlichen Abmachungen sieht, die die Urkunde festhält. Eine von ihnen konkretisiert noch die Art und Weise, wie mit dem oben erwähnten Mann namens Gerlach weiter zu verfahren sei ${ }^{57}$. Sodann verpflichteten sich die Bürger, die alten Rechte von Bischof und Klerus sowie der bischöflichen Ministerialen zu wahren, und sagten zu, in Zukunft dem Stadtherrn und den Seinen Recht widerfahren zu lassen, wenn sich einer von deren Hörigen in der Stadt bis zu Jahr und Tag aufhält. Sollte sich der Betreffende weigern, sich seinem Herrn zu stellen, solle ihn die Gemeinschaft der Bürger ausschließen ${ }^{58}$.

Auf den ersten Blick gibt die Urkunde eine sehr einseitige Vereinbarung wider. Allein die Bürger müssen ihre Schuld eingestehen und eine große Schandprozession durch die Stadt auf sich nehmen. Sie allein gehen laut der schriftlichen Übereinkunft irgendwelche Verpflichtungen ein ${ }^{59}$. Damit erklärt sich

${ }^{54}$, ,...] insuper et hominem quendam Gerlacum, in quo domino episcopo violentiam fecisse dicebantur, nulla interposita conditione dominationi episcopi restituerent. Quo facto in forma compositionis dictum est, ut dominus episcopus de gratia sua expurgationem oblatam a singulis reciperet". Ibidem.

55 „Adiectum est, ut cives domino episcopo infra XIIII ${ }^{\text {cim }}$ dies centum marcas persolverent, et sic eos in plenitudinem gratie sue super novis et veteribus excessibus, quos contra eos intendere poterat, reciperet". Ibidem.

${ }^{56}$ Zur Verbreitung und Entwicklung der Harmschar vgl. J.-M. Moeglin, Harmiscara Harmschar - Hachée. Le dossier des rituels d'humiliation et de soumission au Moyen Age, „Archivium Latinitatis Medii Aevi“" 1996, Vol. 54, S. 11-65.

57 Vgl. bei Anm. 60.

58 „Adiectum est quoque in compositione, quod cives iura episcopi et cleri et ministerialium, sicut $a b$ antiquo statuta fuerunt, illesa servabunt, et hoc idem circa cives servabitur. Quodsi contigerit hominem aliquem proprium episcopi vel ecclesie vel ministerialium civitatem intrare, ipsi cives querelanti plenam iusticiam infra annum et diem exhibebunt; quam si ille de quo querela proponitur exbibere noluerit, eum de consortio suo removebunt". Westfälisches Urkundenbuch, Bd. 4, Nr. 99, S. 69.

${ }_{59}$ Vgl. M. Becher, op. cit., S. 193. 
auch, warum kein Schiedsgericht eingesetzt wurde, um den Konflikt beizulegen. Der Bischof hätte damit das Verhältnis zu seiner Stadt dem Urteil eines Dritten unterworfen, der auch Forderungen der anderen Seite hätte berücksichtigen müssen. Das aber hätte seine unbedingten Rechte als Stadtherr in Frage gestellt, die er mit dieser Sühne gerade demonstrieren wollte.

Anders als in Köln stehen die Bürger dem Tun des Bischofs jedoch nicht mehr machtlos gegenüber und wissen dank der Vermittler, was sie erwartet. Genau kennen sie die Bedingungen, unter welchen sie die Huld ihres Herrn erhalten. Darüber hinaus, und das mag erklären, warum die Städter dem Abkommen zugestimmt haben, führte die Sühne auch zur ihrer Anerkennung als rechtsfähige Gemeinschaft, selbst wenn dies nicht ausgesprochen wurde. So standen die 500 Bürger, die an der Unterwerfung teilnahmen, letztlich für die Stadtgemeinde ein. Sie waren es, die für alle Bürger die Schande auf sich nahmen. Auch wenn sie sich einzeln entschuldigen sollten, sprachen sie damit für die Stadtgemeinschaft, deren Vergehen so gesühnt wurden. Damit unterstrichen sie gleichzeitig deren Handlungsfähigkeit. Mehr noch zeigen die rechtlichen Abmachungen, was die Stadt mit der Unterwerfung gewann: Ihr wurden keine Rechte bestritten, ja das Recht, Hörige nach Jahr und Tag aufzunehmen, wurde indirekt bestätigt. In dem Streit über den Eigenmann des Bischofs, der offenkundig zur Eskalation beigetragen hatte, wurde letztlich ein Kompromiss erzielt, wie er in der damaligen Zeit typisch war. Die Rechte des Bischofs an dem Mann wurden anerkannt, aber der Betroffene durfte erst einmal in der Stadt bleiben und sollte später in der Tat weiterhin als Bürger Rechtsgeschäfte bezeugen ${ }^{60}$. Darüber hinaus wurde den Städtern das Recht zugestanden, aus ihrer Gemeinschaft Personen auszuschließen $^{61}$. Und nicht zuletzt trat die Stadtgemeinschaft als eigene Rechtsinstitution hervor, da sie ihr bei dieser Gelegenheit erstmals überliefertes Siegel unter das Abkommen setzte ${ }^{62}$. Insofern begünstigte die Sühne mitsamt der entehrenden Unterwerfung die städtischen Autonomiebestrebungen. Nicht von ungefähr ist denn auch gut 15 Jahre später in Paderborn ein städtischer Rat nachzuweisen ${ }^{63}$.

60 „Predictus autem Gerlacus cum civibus erit in gratia episcopi, nec imputabit ei episcopus aliquod precedens factum, si quietus erit usque ad nativitatem Domini. Extunc si dominus episcopus eum proprium suum esse voluerit proponere, cives ut in gratia sua componat vel ut stet iusticie fideliter cooperabuntur. Alioquin a consortio suo eum removebunt”. Westfälisches Urkundenbuch, Bd. 4, Nr. 99, S. 69. Zu den Belegen, die für spätere Aktivitäten Gerlachs als Bürger sprechen vgl. S. Käuper, op. cit., S. 39-40.

${ }_{61}$ Vgl. die Zitate in Anm. 58 u. 60.

${ }^{62}$ Vgl. H. Schoppmeyer, op. cit., S. 232-233.

${ }^{63}$ Vgl. ibidem, S. 239-240. 
III.

Eine rituelle Unterwerfung spielte auch im Jahr 1258 eine wichtige Rolle, als der sogenannte Große Kölner Schied eine Auseinandersetzung zwischen dem Erzbischof Konrad von Hochstaden und den Bürgern der Stadt beendete ${ }^{64}$. Angefangen hatte alles mit der Gefangennahme eines angesehenen Kölner Bürgers im Jahr zuvor, den einige Ritter inhaftiert hatten, um einen anderen Kölner Bürger, der ihnen Geld schuldete, unter Druck zu setzen ${ }^{65}$. Die Familie des Inhaftierten ließ die Schmach des Arrestes nicht auf sich sitzen und überfiel einen Kölner Domherrn, der mit dem Lehnsherrn der Ritter verwandt war. Das wiederum forderte den Erzbischof heraus. Er machte sich von seiner Residenz in Bonn auf den Weg nach Köln, umgeben von einer größeren Kriegerschar. Als er jedoch vor dem Severinstor erschien, schlugen ihn bewaffnete Kräfte der Stadt zurück. Der Erzbischof verhängte daraufhin eine Blockade gegen die Stadt, es kam zum Krieg, bei dem der Erzbischof eine militärische Niederlage hinnehmen musste. Auch der Versuch, seine unmittelbaren Vasallen in den Kampf ziehen zu lassen, trug wenig Früchte. Zwar gelang es Graf Adolf von Berg 50 Kölner, die einen Ausfall gewagt hatten, bei Deutz zu töten. Da er aber anschließend von einer Schar Kölner Bürger in die Flucht geschlagen wurde, musste er der Stadt vertraglich versprechen, nicht weiter gegen sie vorzugehen. Den Winter über geschah wohl nicht mehr viel. Die Kölner Bürger konnten sich militärisch behaupten, litten aber andererseits weiter unter der Blockade. So war die Situation, in der es Mitte März $1258 \mathrm{zu}$ Friedensverhandlungen zwischen Konrad von Hochstaden und der Stadt kam, die am 20. März zu einer vorläufigen Einigung führten.

Wahrscheinlich war es Albertus Magnus, der einen entscheidenden Anteil an der späteren Lösung des Konfliktes hatte, der bereits als Vermittler beide Seiten zusammengeführt hatte ${ }^{66}$. Dafür war er prädestiniert. Schon zuvor war er bei mehreren Konflikten als Schlichter oder Schiedsrichter aufgetreten und besaß sowohl das Vertrauen sowohl des Erzbischofs als auch der Kölner Bürger. Ausgerichtet waren in jedem Fall die ersten Verhandlungen darauf, ein Schiedsgericht zu etablieren und dafür die nötigen Vorbedingungen zu schaffen.

${ }^{64} \mathrm{Zu}$ den Umständen, zum Verlauf und zur Bedeutung vgl. M. Groten, Köln im 13. Jahrhundert. Gesellschaftlicher Wandel und Verfassungsentwicklung, Köln-Weimar-Wien 1995, S. 181-193, und die umfassende Studie von D. Strauch, Der Große Schied von 1258. Erzbischof und Bürger im Kampf um die Kölner Stadtverfassung, Köln-Weimar-ien 2008.

${ }^{65} \mathrm{Vgl}$. zum in Folgenden geschilderten Konfliktverlauf M. Groten, op. cit., S. 180ff.; D. Strauch, op. cit., S. 3-7; C. Garnier, op. cit., S. 277-281.

${ }^{66}$ Vgl. hierzu und zum Folgenden H. Stehkämper, ,Pro bono pacis'. Albertus Magnus als Friedensmittler und Schiedsrichter, „Archiv für Diplomatik“1977, Bd. 23, S. 297-382, u. bes. 302, zu Alberts Beteiligung. 
Anders als zuletzt behauptet, zeigt das angestoßenen Verfahren nicht unbedingt einen Erzbischof, der aus einer Position der Stärke verhandelt ${ }^{67}$. Der Vertrag, mit dem beide Seiten die Einrichtung des Schiedsgerichts bekanntgeben, ist bis in alle Einzelheiten auf die Gleichstellung der Konfliktparteien ausgerichtet. Stets ist von den Rechten und Privilegien beider Seiten die Rede, wodurch die Stadt dem Erzbischof als eigenständiger Rechtsträger in Köln gegenübertrat ${ }^{68}$. Dass in der Urkunde die Bürgermeister und Ratsleute nicht unter den Vertretern der Stadt erwähnt werden, ist nicht auf den Wunsch des Bischofs zurückzuführen, seine Hauptgegner zu übergehen ${ }^{69}$. Schon beim ersten Schied zwischen dem Erzbischof und seiner Stadt von 1252 erscheinen die Bürgermeister und die Ratsleute nicht. Die Stadt wird hier sogar nur mit den Schöffen und den Bürgern gleichgesetzt ${ }^{70}$. Ohnehin ist bei vielen Verträgen, die die Stadt selbst abschloss, oder bei Privilegien, die sie von weltlichen Herren erhielt, nur von den Richtern, Schöffen und Bürgern die Rede, die für die Stadtgemeinschaft stehen ${ }^{71}$. Insofern ist der Sprachgebrauch nicht auffällig und deutet kein Übergewicht des Bischofs an.

Auch die Zusammensetzung des Schiedsgerichts zeugt von Gleichbehandlung. Berufen wurden vier Mitglieder des Domkapitels, von denen zwei mehr oder minder Gefolgsleute des Bischofs waren, während man den beiden anderen Sympathien für die Stadt nachsagt ${ }^{72}$. Hinzu trat mit Albertus Magnus eine fünfte

67 So M. Groten, op. cit., S. 184.

68 Vgl. Quellen zur Geschichte der Stadt Köln, hrsg. v. L. Ennen, Bd. 2, 1863, Nr. 381, S. 376377: ,Wir Cunraid erchebisschoff van Colne Inde wir Rihtere, Scheffenen inde gemeinliche de burgere van Colne dûn dat kunt allen den die diesen brief sient. [...] So wa vnsis gestihtis Reht, vriheit, gude inde redeliche gewoneden inde hantuestingen vntzwiflig sint, dat wir inde vnse gestihte da ane sitzen inde bliuen gerûliche, vp andir side, so wa der stede Reht van Colne, vriheide, gûde inde redelighe gewoneden Inde hantuestingen vnzwiflig sint, da sal de stat inde de burgere van Colne inne sitzen inde bliuen gerûlighe. So wa euer oue an wat punten wir erchebisschof spregghen, dat de stat oue de burgere van Colne vnreht dûn vns oue den vnsen oue vnseme gestihte van Colne, Inde up ander side, so wa wir burgere spregghen, dat vnse here der erchebisschof vns oue den vnsen oue der stede van Colne vnreht dû, dan af zweiinge oue zwiuel kûmen is oue kûmen magh, alles des sin wir in beidenthaluen gegangen an vûnf man bit namen [...]“. Vgl. auch D. Strauch, op. cit., S. 22-23.

69 So ibidem.

${ }^{70}$ Vgl. Quellen zur Geschichte Bd. 2, Nr. 306, S. 312. Als 1248 Erzbischof Konrad von Hochstaden den Kölner ihre Freiheiten und Rechte bestätigte, spricht er dabei ebenfalls nur von den Schöffen und Bürgern (Nr. 279, S. 283). Auch Innozenz IV. spricht in mehreren Urkunden für die Kölner nur die Richter, Schöffen und Bürger als Repräsentanten der Stadt an (ibidem, Nr. 312, S. 326; Nr. 314, S. 328; Nr. 315, S. 329; Nr. 320, S. 334). Ohnehin werden die Bürgermeister kaum genannt, das Privileg Konrads für die Juden von 1259 (ibidem, Nr. 308, S. 321) ist eher die Ausnahme.

71 Vgl. ibidem, Nr. 251, S. 253; Nr. 296, S. 298. Zuweilen ist sogar nur von den Kölner Bürgern die Rede (Nr. 299, 302-303; Nr. 302, S. 307; Nr. 321, 335).

${ }^{72}$ Vgl. zur Ernennung der Schiedsrichter ibidem und zu ihrer Einordnung ausführlich H. Stehkämper, Pro bono..., 297-382, hier 329-331, und D. Strauch, op. cit., 11-20, sowie M. Groten, op. cit., S. 185. 
Person, der offenkundig bei einem Patt die Aufgabe zukommen sollte, eine Entscheidung herbeizuführen. Dass das Schiedsgericht aus Personen bestand, die rechtlich dem Erzbischof unterstanden, wurde gleichsam durch die Berufung des unabhängigen Albertus Magnus wettgemacht, der zu keiner der Parteien in einem Abhängigkeitsverhältnis stand $\mathrm{d}^{73}$.

Weniger paritätisch kommt auf den ersten Blick die ebenfalls am 20. März vermittelte Vereinbarung über die Sühnebedingungen daher. Zwar legt sie gleich zu Anfang fest, dass die umstrittenen Bierpfennige für die kommenden zehn Jahre zwischen Bischof und Stadt geteilt werden sollen ${ }^{74}$. Dann aber ist von der Genugtuung die Rede, die die Bürger dem Bischof in Form der rituellen Unterwerfung zu leisten haben. So sollten diejenigen, die den Domherrn angegriffen hatten, vom Severinstor zum Judenbüchel, der alten Gerichtsstätte, barfuß und in härenem Gewand gehen und dort die Gnade des Bischofs suchen ${ }^{75}$. Zudem hatten sie eine materielle Buße an das Domkapitel zu leisten. Gegenüber dem Erzbischof waren sie mit dem rituellen Akt ihrer Schuld enthoben ${ }^{76}$. Von den anderen Bürgern der Stadt wurde verlangt, der Sühneprozession zu folgen und den Bischof um Gnade zu bitten. Sie mussten keine Bußkleidung anlegen, was gerade gegenüber den bisher betrachteten deditiones als ein Privileg erscheint ${ }^{77}$. Im Gegenzug nahm der Bischof die Bürger in seine Huld, was insofern konkretisiert wurde, als er damit für alle bis zu diesem Tage begangenen Vergehen der Kölner Stadt zu verzeihen versprach und auf Entschädigungsleistungen jedweder Art verzichtete, was die Stadt ebenso tat ${ }^{78}$. Zu allerletzt musste

${ }^{73}$ Vgl. H. Stehkämper, Pro bono..., S. 331, u. D. Strauch, op. cit., S. 19-20 der Albert als „neutrale Person“ bezeichnet.

74 Vgl. Quellen zur Geschichte, Bd. 2, Nr. 382, 378-379, S. 378: „Die birpenninge van der zit, dat si vzgient, sal man si lengen zien iaer. Di sal niemen half di bischof Inde half die stait“"

75 „Di giene, die herin Henrichen van der Nuwerburg ane taisten, di sulen alsus bezzeren. Sie sulen kûmen gande wullin inde barevûz vûr den anderin burgerin van sente Seuerins porzen biz an den jûdenbuchil Inde sulen gnaide da sûchin des erchebischouis". Quellen zur Geschichte, Bd. 2, Nr. 382, S. 378. Zur Symbolik cf. C. Garnier, op. cit., S. 280.

76 „Inde bit der bezzeringe sal ieme genugin, auer die bezzeringe, di geschien sal herin Henrichen inde dieme da sûchin des erchebischouis Inde bit der bezzeringe sal ieme genûgin, auer die bezzeringe, di geschien sal herin Henrichen inde dieme Capitele vamme Dûme, di steit an deine Capitele ane heflich guit".

77 „Die bezzeringe van der stait is alsus. Die gûde lude van der stait, di sulen gien van sente seuerins porzen biz an den judenbuchil Inde sulen da des erchebischouis gnaide suchen“. Quellen zur Geschichte, Bd. 2, Nr. 382, S. 378.

78 „Inde da mide sal ime der bischof lazin genûgen. Inde sal da verzien allirhande brûghe inde van allirhande vorderunge, si sin van doiden of van leuindigen of van roiue of van brande, inde van allirhande saghen, alt inde nuwe, di he zesprechene hadde bit an disen nemlichen daich, vp die stait van Colne. Inde dit verzighnisse sal gain vur inne inde vur alle sine helpere vp die stait van Colne inde op den herin van valkenburg inde alle ire helpere. Dit selue verzighnisse sal duen die stait van Colne vp den erchebischof inde sine helpere vûr si inde vûr alle ire helpere, also dat id si in beidenthaluen eine ganze vruede“. Ibidem. 
sich die Stadt Köln bereit erklären, dem Bischof einen neuen Treueid zu schwören, während dieser geloben sollte, ein guter Herr zu sein ${ }^{79}$. Wenn man sich schon einer Unterwerfung unterziehen musste, konnte man kaum besser davonkommen.

Dieser Eindruck wird auch nicht Frage gestellt, wenn man in der Regelung, die Bierpfennige jeweils zur Hälfte aufzuteilen, vor allem einen Verhandlungserfolg des Erzbischofs sieht, da dieser 1240 auf seinen Anteil an der Steuer verzichtet hatte $^{80}$. Die erneute Beteiligung an der Steuer entspricht nämlich in gewisser Weise den Geldsummen, die zuweilen im Zusammenhang einer Unterwerfung als Wiedergutmachung für den Ungehorsam an den Herrn gezahlt wurden ${ }^{81}$. Stimmt dies, dann scheint selbst in diesem Punkt der Bischof seine vermeintliche Stärke kaum ausgespielt und es nicht darauf angelegt zu haben, die Bürger gar zu demütigen, wurde doch die Zahlung der Genugtuungsleistung in einer paritätisch aufgeteilten Steuer unsichtbar gemacht.

Wie schon in Paderborn bildete auch in Köln 1258 die Unterwerfung die Voraussetzung für die Regelung der rechtlichen Fragen, die nun aber einem regelrechten Schiedsgericht anvertraut wurde, dem sich die beiden Parteien vorab unterwarfen ${ }^{82}$. Beide Seiten wurden gebeten, ihre Klagen über die jeweils andere Seite vorzulegen, die dann auch in das abschließende schriftlich ausgefertigte Urteil aufgenommen wurden ${ }^{83}$. Mit diesem Verfahren besaßen die Parteien die Sicherheit, dass nur über die Angelegenheiten entschieden wurde, die sie selbst bestimmt hatten. Der seitenlange Schiedsspruch, der dann jeweils über die Klagen des Erzbischofs und über die der Bürger ein Urteil fällte ${ }^{84}$, erscheint im Großen und Ganzen ausgeglichen. Zwar stimmen die Schiedsrichter der Forderung des Erzbischofs grundsätzlich zu, die höchste Amtsgewalt und Gerichtsbarkeit auch in weltlichen Angelegenheiten in der Stadt zu besitzen, aber zugleich schränken sie seine Stellung wieder ein, indem sie die städtischen Organe allesamt und namentlich die gerichtlichen Befugnisse der Bürgermeister, die allein den Bürgern durch einen Eid verpflichtet waren, anerkannten ${ }^{85}$. Selbst der 1216 noch aufgelöste

79 „Dar na sal di stait irnuwen ire hulde deme erchebischoue bit dime eyde alse gewonlich is. Inde hie sal in wieder gelouin bit gûdin truwen, dat hie in gut inde ein gnedich here sal wesin. Inde sal si beschirmen alse zereghte ein erchebischof sine burgere". Ibidem.

${ }^{80}$ Vgl. M. Groten, op. cit., S. 184 und C. Garnier, op. cit., S. 279.

${ }^{81}$ Vgl. H. Kamp, op. cit., S. 204, und K. Görich, Geld und Ehre: Friedrich Barbarossa, [in:] Geld im Mittelalter, hrsg. v. K. Grubmüller, M. Stock, Darmstadt 2005, S. 113-134, S. $122-125$.

${ }^{82}$ Vgl. den Vertrag über die Einsetzung des Schiedsgerichts in: Quellen zur Geschichte, Bd. 2, Nr. 381, S. 377.

${ }^{83}$ Vgl. ibidem und dazu D. Strauch, op. cit., S. 24-32.

${ }^{84}$ Vgl. D. Strauch (op. cit.) mit der Wiedergabe des Spruchs über die bischöflichen Klagen S. 219-237 und des Spruchs über die Klagen der Stadt S. 238-245.

${ }^{85}$ Vgl. ibidem, S. 174-181 mit einer Auflistung der Regelungen, die die Klagen der jeweiligen Parteien bestätigen oder zurückweisen. 
Rat wurde für rechtens erklärt ebenso wie das Verlangen der Stadt, Bündnisse mit auswärtigen Mächten schließen zu können ${ }^{86}$.

Auch wenn sich der Kölner Erzbischof ein Jahr später auf den Großen Schied und seine Missbrauchsparagraphen berief, um gegen die regierenden Schöffen vorzugehen und sie durch neue, aus anderen Familien stammende zu ersetzen ${ }^{87}$, war das Kölner Schiedsurteil von 1258 ein Dokument, das die im 12. und 13. Jahrhundert gewonnene Autonomie der Stadt absicherte, ihre Einrichtungen anerkannte und ihre wirtschaftlichen Privilegien präzisierte. Und so wurde im Rahmen der Konfliktbeilegung von 1258 nichts anderes geschaffen als eine erste Kölner Stadtverfassung ${ }^{88}$.

Dass der Schied von 1258 die ihm vorausgehende Unterwerfung schnell vergessen machte, liegt auf der Hand. Dennoch spielte sie für die Konfliktbeilegung eine entscheidende Rolle. Denn während der Schied die hinter dem Konflikt stehenden Probleme im Verhältnis zwischen Stadtherr und Stadt zu lösen suchte, diente die Unterwerfung dazu, die am Anfang und im Laufe der Auseinandersetzung begangenen Untaten zu sühnen respektive den Verzicht auf alle weiteren Genugtuungs- bzw. Entschädigungsleistungen festzuschreiben, wie das ansonsten bei Friedensverträgen inzwischen der Fall war ${ }^{89}$. Indem zugleich zwischen den Missetätern und den Vertretern der Stadt symbolisch unterschieden wurde, erscheint die Stadt als eine eigenständige, übergeordnete Größe, die dann auch für alle Bürger auf bestimmte Ansprüche verzichten konnte. Vor allem aber wird die Bedeutung der deditio in dem anschließenden Treueid gegenüber dem Bischof sichtbar. Er erneuerte die durch den Konflikt zerbrochenen Bindungen zwischen Stadtherr und Bürgerschaft und schuf damit die Voraussetzungen für die Einrichtung eines gemeinsamen Schiedsgerichts und die genauere Festlegung der jeweiligen Rechte und Verpflichtungen. Daher erscheint diese deditio vor allem als ein politischer Akt, der gerade für die beteiligten Vertreter der Stadt seine religiöse Bedeutung eingebüßt hatte.

Je nach politischer Lage und Entwicklungsstand der städtischen Autonomie besaß eine rituelle Unterwerfung ein anderes Gepräge, vor allem aber eine andere Funktion. Am stärksten religiös eingebunden erscheint die deditio der Kölner Bürger von 1074. In der Paderborner Unterwerfung wird man primär einen Akt sehen, der die verlorene Ehre des Bischofs wiederherstellen sollte, während es

${ }^{86}$ Vgl. ibidem.

87 Vgl. M. Groten, op. cit., S. 191-206.

${ }^{88}$ Vgl. D. Strauch, op. cit., S. 189. Auch H. Stehkämper, Pro bon...o ..., S. 357-359, sieht vor allem die Stadt als Nutznießer des Großen Schieds. Letztlich erkennt auch M. Groten, op. cit., S. 191 die Ausgewogenheit des Schieds an, betont aber nur, dass er für den Bischof in der Praxis zu einem wirkungsvollen Mittel im Kampf gegen die führenden Kölner Geschlechter wurde.

${ }^{89}$ Vgl. J. Fisch, Krieg und Frieden im Friedensvertrag. Eine universalgeschichtliche Studie über Grundlagen und Formelelemente des Friedensschlusses, Stuttgart 1979, S. 78-80. 
1258 in Köln vor allem um die Erneuerung der Herrschaftsbeziehungen zwischen Bischof und Stadt ging. Die frühe Kölner Unterwerfung von 1074 steht für die Behauptung eines ungeminderten anschließenden Strafanspruchs des Stadtherrn, dem auch deshalb nur geringe Grenzen gesetzt waren, weil es keine Vermittler gab, die ihn auf ein bestimmtes Verhalten hätten verpflichten können. Das war 1222 in Paderborn bereits anders, als die Vermittler nicht nur informell tätig wurden, sondern schriftlich fixierten, wie der Streit zwischen dem Bischof und der Stadt beigelegt werden sollte. Dabei gab sich der Stadtherr mit der Auferlegung einer Geldbuße und der Bekräftigung der stadtherrlichen Rechte zufrieden, womit er zugleich die Stadtgemeinde als solche mit bestimmten Rechten anerkannte. Auch wenn dies nur ein erster Schritt auf dem Weg zur Autonomie war, so zeigt sich gerade im Vermittlungsverfahren selbst das gestiegene Prestige der städtischen Oberschichten, die von den vermittelnden Domherren und den bischöflichen Ministerialen als Gesprächs- und Verhandlungspartner anerkannt wurden. Noch deutlicher reflektiert die Konfliktbeilegung 1258 in Köln die für Bischofsstädte relativ stark ausgeprägte städtische Eigenständigkeit. Hier agierten sogar Vermittler, die den Bischof darauf verpflichten konnten, einen zweiseitigen, paritätisch aufgebauten Vertrag zu unterzeichnen, mit dem ein Schiedsgericht eingesetzt wurde, und einen zweiten Vertrag, der dem Bischof Wiedergutmachung durch einen Anteil an einer Steuer, den Bußgang der Missetäter und die Prozession der unbescholtenen Bürger zukommen ließ, aber ihm zugleich den Verzicht auf weitere Entschädigungen abverlangte. Diese Vermittler trugen so zur Konfliktlösung bei, überließen aber die Ausarbeitung des Friedensschlusses den Schiedsrichtern. Insofern erscheinen dann auch die Schiedsmänner als die eigentlichen Friedensstifter, deren Namen im Unterschied zu denen der Vermittler überliefert wurden. Da sich Bischof und Stadt in gleicher Weise vorab dem Urteil der Schiedsleute unterwarfen, wie dies bei Schiedsverfahren üblich war, erfuhr die Stadt als eigene Rechtsgemeinschaft nicht nur eine Aufwertung, sondern wurde als Konfliktgegner dem Bischof gleichgestellt, weshalb der Rekurs auf das Schiedsverfahren der deutlichste Indikator für die faktische oder zumindest erstrebte Eigenständigkeit der Stadt ist. Für deren Anerkennung nahm die Stadt dann auch die Akte der Selbstdemütigung hin.

Was sich in Paderborn 1222 bereits ankündigt, macht die Beendigung des Konfliktes in Köln 1258 in aller Deutlichkeit sichtbar: der Stellenwert der rituellen Unterwerfung nahm im Rahmen der Konfliktbeilegung ab. Die Abgrenzung und der Abgleich der Rechtsansprüche zwischen Stadtherr und Stadt trat gegenüber der Bestrafung des Ungehorsams in den Vordergrund. Das wurde auch möglich, weil mit dem Schiedsverfahren inzwischen ein geeignetes Mittel für diesen Zweck zur Verfügung stand. Dass es in den Bischofsstädten erst im 13. Jahrhundert zum Einsatz kam, lag auch an der erst jetzt erreichten Autonomie der Städte, deren damalige Grenzen im Schiedsverfahren selbst zu erkennen sind, entsandten doch die Kölner auch noch 1258 keine eigenen Vertreter in das Schiedsgericht. 
Dennoch konnte die wachsende Autonomie die rituelle Unterwerfung nicht ganz verdrängen. Sie blieb ein sinnvolles Instrument, um Vergehen zu benennen und zu vergeben, um die Ehre des Stadtherrn wiederherzustellen und um Herrschaftsverhältnisse sichtbar neu zu begründen. Und wenn der bischöfliche Stadtherr die Bürger zuvor exkommuniziert hatte, war sie auch weiterhin ein probates Mittel, um den Sündern die Wiederaufnahme in die Kirche zu bahnen, wie man es in Köln 1265 erneut beobachten kann ${ }^{90}$. Und doch rückten mit der wachsenden Autonomie der Städte deren Rechte und die Befugnisse ihrer Amtsträger ins Zentrum der Verhandlungen, wenn ein Konflikt mit dem Stadtherrn beigelegt werden sollte. Damit aber sank die rituelle Unterwerfung zu einer, wenn auch zuweilen unverzichtbaren Vorleistung herab.

\section{LITERATURVERZEICHNIS}

\section{Quellen}

Die Hildesheimer Briefe, [in:] Die Briefsammlungen der Zeit Heinrichs IV., hrsg. v. C. Erdmann, N. Fickermann, Weimar 1950.

Lampert von Hersfeld, Annales, hrsg. v. O. Holder-Egger, Hannover-Leipzig 1894.

Quellen zur Geschichte der Stadt Köln, hrsg. v. L. Ennen, Bd. 2, 1863.

Vita Annonis archiepiscopi Coloniensis, hrsg. v. R. Köpke, Hannover 1854, S. 462-518.

Westfälisches Urkundenbuch, Bd. 4: Die Urkunden des Bisthums Paderborn vom J. 1201-1300, Erste Abteilung: Die Urkunden der Jahre 1201-1240, bearb. v. R. Wilmans, Münster 1874 ND, Osnabrück 1973.

Westfälisches Urkundenbuch, Bd. 4: Die Urkunden des Bisthums Paderborn vom J. 1201-1300, Dritte Abteilung: Die Urkunden der Jahre 1251-1300, bearb. v. H. Finke, Personen- und Ortsregister bearb. v. H. Hoogeweg, Münster 1894.

\section{Literatur}

Althoff G., Das Privileg der deditio. Formen gütlicher Konfliktbeendigung in der mittelalterlichen Adelsgesellschaft, [in:] Spielregeln der Politik im Mittelalter. Kommunikation in Frieden und Fehde, Darmstadt 1997, S. 99-125.

Althoff G., Die Macht der Rituale. Symbolik und Herrschaft im Mittelalter, Darmstadt 2007.

Althoff G., Otto III., Darmstadt 1996.

Arnade P., Realms of Rituals. Burgundian Ceremony and Civic Life in Late Medieval Ghent, IthacaLondon 1996.

Becher M., Zwischen Reichspolitik und regionaler Orientierung: Paderborn im Hochmittelalter (1050-1200), [in:] Paderborn. Geschichte der Stadt in ihrer Region, Bd. 1: Das Mittelalter. Bischofsherrschaft und Stadtgemeinde, hrsg. v. J. Jarnut, Paderborn 2000, S. 121-196.

${ }^{90}$ In jenem Jahr mussten sich die Kölner und ihre Amtsträger erneut vor ihrem damaligen Erzbischof Engelbert II. von Valkenburg in Büßeraufzug demütigen. Sie hatten ihn zuvor eine Weile gefangen gesetzt, worauf er das Interdikt ausgesprochen hatte. Vgl. dazu C. Garnier, op. cit., S. 281-284. 
Ennen E., Bischof und mittelalterliche Stadt. Die Entwicklung in Oberitalien, Frankreich und Deutschland, [in:] Gesammelte Abhandlungen zum europäischen Städtewesen und zur rheinischen Geschichte, Bonn 1977, S. 40-52.

Fisch J., Krieg und Frieden im Friedensvertrag. Eine universalgeschichtliche Studie über Grundlagen und Formelelemente des Friedensschlusses, Stuttgart 1979, S. 78-80.

Garnier C., Zeichen und Schrift. Symbolisches Handeln und literale Fixierung am Beispiel von Friedensschlüssen im 13. Jahrhundert, „Frühmittelalterliche Studien“1998, Bd. 32, S. 263-287.

Görich K., Die Ehre Barbarossas. Kommunikation, Konflikt und politisches Handeln im 12. Jahrhundert, Darmstadt 2001.

Görich K., Geld und Ehre: Friedrich Barbarossa, [in:] Geld im Mittelalter, hrsg. v. K. Grubmüller, M. Stock, Darmstadt 2005, S. 113-134.

Groten M., Köln im 13. Jahrhundert. Gesellschaftlicher Wandel und Verfassungsentwicklung, KölnWeimar-Wien 1995.

Isenmann E., Die deutsche Stadt im Mittelalter 1150-1550: Stadtgestalt, Recht, Verfassung, Stadtregiment, Kirche, Gesellschaft, Wirtschaft, Köln-Weimar 2014.

Jenal G., Erzbischof Anno II. von Köln und sein politisches Wirken. Ein Beitrag zur Geschichte der Reichs- und Territorialpolitik im 11. Jahrhundert, 2 Bde., Stuttgart 1974.

Kamp H., Friedensstifter und Vermittler im Mittelalter, Darmstadt 2001.

Käuper S., Aufstand und Kommunebildung im 13. Jahrhundert. Zwei Fälle aus Paderborn, [in:] Bischof und Bürger. Herrschaftsbeziehungen in den Kathedralstädten des Hoch- und Spätmittelalters, hrsg. v. U. Grieme, N. Kruppa, S. Pätzold, Göttingen 2004, S. $27-66$.

Lück D., Erzbischof Anno II. von Köln. Standesverhältnisse, verwandtschaftliche Beziehungen und Werdegang bis zur Bischofsweihe, „Annalen des Historischen Vereins für den Niederrhein“ 1970, Bd. 172, S. 7-112.

Meyer von Knonau C., Jahrbücher des deutschen Reiches unter Heinrich IV. und Heinrich V., Bd. 2, Leipzig 1890.

Militzer K., Der Aufstand der Kölner gegen Erzbischof Anno II. von 1074, [in:] In tempore belli et pacis. Ludzie - miejsca - przedmioty. Ksiega pamiatkowa dedykowana prof. dr. hab. Janowi Szymczakowi w 65-lecie urodzin i 40-lecie pracy naukowo-dydaktycznej, Warszawa 2011.

Moeglin J.-M., Harmiscara - Harmschar - Hachée. Le dossier des rituels d'humiliation et de soumission au Moyen Age, „Archivium Latinitatis Medii Aevi“ 1996, Vol. 54, S. 11-65.

Moeglin J.-M., Pénitence publique et amende honorable au Moyen Age, „Revue Historique 298“ 1997, Vol. 298, S. 225-269, bes. 226-227.

Neddermeyer U., Aufstand gegen den Erzbischof 1074: Lampert von Hersfeld berichtet, [in:] Quellen zur Geschichte der Stadt Köln, Bd. 1: Antike und Mittelalter. Von den Anfängen bis 1396/97, hrsg. v. W. Rosen, L. Wirthler, Köln 1999, S. 109-132.

Schieffer R., Art. Lampert von Hersfeld, [in:] Die deutsche Literatur des Mittelalters. Verfasserlexikon, Bd. 5, Berlin-New York 1985, S. 513-520.

Schlick J., König, Fürsten und Reich 1056-1159. Herrschaftsverständnis im Wandel, Stuttgart 2001.

Schoppmeyer H., Die spätmittelalterliche Bürgerstadt (1200-1600), [in:] Paderborn. Geschichte der Stadt in ihrer Region, Bd. 1: Das Mittelalter. Bischofsherrschaft und Stadtgemeinde, hrsg. v. J. Jarnut, Paderborn 2000, S. 199-473.

Schreiner K., ,Nudis pedibus'. Barfüßigkeit als religiöses und politisches Mittel, [in:] Formen und Funktionen öffentlicher Kommunikation im Mittelalter (Vorträge und Forschungen 51), hrsg. v. G. Althoff, Stuttgart 2001, S. 53-124.

Schulz K., ,Denn sie lieben die Freiheit so sehr...'. Kommunale Aufstände und Entstehung des europäischen Bürgertums im Hochmittelalter, 2. Aufl., Darmstadt 1995.

Stehkämper H., Die Stadt Köln in der Salierzeit, [in:] Die Salier und das Reich, Bd. 3: Gesellschaftlicher und ideengeschichtlicher Wandel im Reich der Salier, hrsg. v. St. Weinfurter, 2. Aufl., Sigmaringen 1992, S. 75-152. 
Stehkämper H., ,Pro bono pacis'. Albertus Magnus als Friedensmittler und Schiedsrichter, „Archiv für Diplomatik“ 1977, Bd. 23, S. 297-382.

Strauch D., Der Große Schied von 1258. Erzbischof und Bürger im Kampf um die Kölner Stadtverfassung, Köln-Weimar-Wien 2008.

Vollrath H., Konfliktwahrnehmung und Konfliktdarstellung in erzählenden Quellen des 11. Jahrhunderts, [in:] Die Salier und das Reich, Bd. 3: Gesellschaftlicher und ideengeschichtlicher Wandel im Reich der Salier, hrsg. v. St. Weinfurter, 2. Aufl., Sigmaringen 1992, S. 279-296.

Zey C., Vormünder und Berater Heinrichs IV. im Urteil der Zeitgenossen (1056-1075), [in:] Heinrich $I V$, hrsg. v. G. Althoff, Ostfildern 2009, S. 87-125.

\section{SUMMARY}

This article deals with the function and significance of ritual submission as a means of settling conflicts between citizens and their episcopal lords in the Roman-German empire before 1300 . On the basis of the Cologne submissions of 1074 and 1258 as well as the ritual of self-humiliation of the Paderborn townspeople in 1222, it is exemplified that the increasing autonomy of the cities are reflected even in the submissions which at first glance symbolize the strong subordination of the civic community. The first example, the famous submission of the citizens of Cologne in 1074, showing a strong debt to the forms of the ecclesiastical penance stands for the assertion of the princely lord to punish his citizens hardly even after the submission. This was due to the fact that there were no intermediaries who could have committed the bishop to a lenient behavior. In this respect, the engagement of mediators in the other two conflicts reveals the growing prestige of the urban upper classes, which were now recognized as negotiating partners, to whom the peacemakers entered into a bond. While in Paderborn only the bishop's claims were included in the expiatory record, two documents treating both parties in balance were set up at the end of the Cologne conflict of 1258, and an arbitration court was established to deal with the complaints of both sides. Thus, in the conflict-resolution process the city was put on the same level as the bishop. This example, too, clearly shows how the importance of ritual submission as a means of resolving such conflicts diminished, as, in he $13^{\text {th }}$ century, the clarifying and arranging of the legal rights of the princely lord and of the civic community came to the fore against the punishment of disobedience. As a result, the arbitration became the focus of conflict resolution. Nevertheless, with the growing autonomy of the cities, the ritual submission didn't disappear. It remained a useful instrument to indicate an offence, to forgive it, to restore excommunicated sinners to the Church, to restore the honor of the princely-lord or to re-establish the bonds of domination.

Keywords: Submission; Cologne 1074; Lampert von Hersfeld; Ecclesiastical Penance; Mediation; Paderborner Reconciliation of 1222; Urban Autonomy; Arbitration

\section{STRESZCZENIE}

Artykuł dotyczy funkcji i znaczenia rytualnego poddania się jako środka rozwiązywania konfliktów między mieszczanami a ich biskupimi panami miasta na obszarze średniowiecznego Cesarstwa Rzymskiego przed rokiem 1300. Pierwszy analizowany przykład źródłowy to słynne poddanie się mieszczan Kolonii w 1074 r., wykazujące daleko idące zapożyczenia form aktu z rytuału kościelnej pokuty. Wydarzenie wyrażało potwierdzenie praw pana miasta do karania jego mieszkańców, nawet po ich podporządkowaniu się woli władzy. Fakt ów spowodowany był - oprócz zdecydowanej przewagi pana gruntowego - brakiem pośredników, którzy mogliby 
skłonić biskupa do ugody. Zaangażowanie mediatorów w dwóch pozostałych opisanych w tekście konfliktach ukazuje wzrastający prestiż miejskich warstw wyższych, postrzeganych od tej pory jako partnerzy w negocjacjach. Podczas gdy w protokole ekspiacyjnym z Paderborn uwzględniono jedynie żądania biskupa, to w końcowej fazie konfliktu kolońskiego z 1258 r. wystawiono dwa dokumenty traktujące obie strony równo, a sąd arbitrażowy został ustanowiony do rozpatrywania skarg obu stron. W ten sposób w procesie rozwiązywania konfliktu miasto traktowano na równi z biskupem. Przykład ten pokazuje również wyraźne osłabienie znaczenia rytualnego poddania się jako narzędzia rozwiązywania takich konfliktów, podczas gdy na pierwszy plan wysuwało się wyjaśnianie i określanie praw przysługujących panu oraz wspólnocie miejskiej. W rezultacie tego procesu arbitraż stał się kluczowym sposobem rozwiązywania konfliktu. Niemniej, nawet w sytuacji rosnącej autonomii miast, rytualne poddanie się buntowników przeciwko władzy nie zanikło - pozostało użytecznym instrumentem wskazywania obrazy, wybaczania jej, przywracania ekskomunikowanych grzeszników na łono Kościoła, respektowania honoru pana, ponownego zacieśnienia zerwanych więzów zależności.

Słowa kluczowe: poddanie; Kolonia 1074; Lampert von Hersfeld; pokuta kościelna; mediacja; pojednanie w Paderbornie z 1222 r.; autonomia miejska; arbitraż 